\title{
Bridging the Gap between the Bench and the Bedside
}

\author{
Ajit Shinto* \\ Department of Nuclear Medicine and PET/CT, Kovai Medical Center and Hospital \\ Limited, India
}

*Corresponding author: Ajit Shinto, Head of Department and Chief Consultant, Nuclear Medicine Dept, KMCH, Coimbatore, Tamilnadu-14, India, Tel: 9943689475;

Email: ajitshinto@gmail.com

\section{Editorial}

There are some episodes in life that can leave an indelible impression on your brain and can serve as a turning point on the way you think and lead your life. I had just experienced one of them; in which $I$ in the capacity of a doctor, was called on to resuscitate an aged person, who was unresponsive in the compartment next to me while traveling on a train in India.

It was the most helpless situation, in which I had to initiate CPR on the aisle of the train and then, physically shift the patient on to a railway platform to continue with my effort, finally resulting in him sputtering back to life. But what really struck me was the general non involvement or callousness of the people around me and even the police to lend a helping hand, fetch support, call an ambulance or even get an oxygen supply going.

It is thus that I reflected that we would stop living if we were immune to the suffering of people around us. Life is a game of chance that brings us to the choices we make. We as health care professionals in the ambit of Nuclear Medicine are at a unique position to make choices that can impact patients lives, not only with what is currently available but with the immense potential for molecular targeting that could make personalised medicine a reality. The ragnosis via molecular probes, biochemical pathways and cellular targets that are unique to each cancer, their expression being so varied between different patients being a principle that Nuclear Medicine has utilised for the past so many decades.

Since the application of I-131 for diagnostic and therapeutic use, to SSTR targets, PSMA peptides to monoclonal antibodies, we have come a long way in identifying newer targets \& enhancing therapeutic options available to clinicians. It is at such a time that a young researcher should remember that the ultimate aim for developing any product is clinical applicability and benefit to a patient. It should not be seen as a $\mathrm{PhD}$ thesis or another research publication. We see all around us scientists striving to publish their studies and once having received an acceptance, there is no further enhancement to that development and it does not see the light of day in our clinics.

So the beginning of any research should ideally focus on a clinical or patient related problem which needs to be solved. Thus it would be easier for the clinical community to be supportive of the project and there would be the cohesion between bench research and clinical research; which is currently lacking.

The future of medicine lies at the bench side, not the bedside and there is a pressing need for both these sides to be communicative with each other, assess the problems and potential solutions, before embarking on any new project or product.

The challenges of funding, corporate support and inabilities to do widespread RCT's for new molecular targets in Nuclear Medicine shall remain. But at least, with the unity of basic research and clinical research ideology, there is hope of regionalised solutions to patient care based on the social, economic and logistical challenges of that specific region.

As an example, Y-90 based microspheres are the gold standard for TARE the world over. However there are less than 150 such procedures done yearly in a highly populated country such as India, due to the prohibitive 


\section{International Journal of Nuclear Medicine \& Radioactive Substances}

cost. Hence, India is at the forefront of research on Re188 based TARE agents, as it is a much more affordable isotope with generator based availability and a dynamic radiochemistry.

Some products succeed because they are destined to, but most products succeed because they have people who are determined behind them.
My exhortation would be to not insulate yourself in a lab, to not be immune to the suffering around you, to open your mind to the possibilities of enhancement of patient care and there you shall find the basis of an exciting product that could change the lives of so many. 